Current Themes in Psychiatry 1 


\title{
Current Themes in Psychiatry 1
}

\author{
Raghu N. Gaind
}

Physician in Psychological Medicine,

Guy's Hospital, London

\section{Barbara L. Hudson}

\section{Lecturer in Applied Social Studies.}

University of Oxford

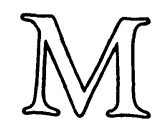


(C) Raghu N. Gaind and Barbara L. Hudson 1978

Softcover reprint of the hardcover 1st edition 1978

All rights reserved. No part of this publication may be reproduced or transmitted, in any form or by any means. without permission

First published 1978 by

THE MACMILLAN PRESS LTD

London and Basingstoke

Associated companies in Delhi Dublin

Hong Kong Johannesburg Lagos Melbourne

New York Singapore and Tokyo

British Library Cataloguing in Publication Data

Current themes in psychiatry 1

1. Psychiatry

I. Gaind, Raghu N II. Hudson, Barbara L

$6168^{\prime} 9$

RC454

ISBN 978-1-349-03644-8 ISBN 978-1-349-03642-4 (eBook)

DOI 10.1007/978-1-349-03642-4

This book is sold subject to the standard

conditions of the Net Book Agreement 


\section{Contents}

List of Contributors $\quad$ ix

Preface xi

Foreword xiii

Acknowledgements $\quad$ xv

SECTION 1 ISSUES OF CONTEMPORARY CONCERN

1 Psychiatric indications for termination of

pregnancy

Robert G. Priest

2 The psychiatry of kidnapping and hostage-taking

Peter D. Scott

3 The treatment of psychopaths

John Gunn

4 Current status of the parental causation hypothesis in schizophrenia

Steven R. Hirsch

5 Mental health policy: pros and cons

Alan R. Norton

SeCtion 2 Specific issues

6 Laterality in relation to psychiatry:

an introduction

John J. Fleminger

7 Some psychophysiological aspects of anxiety

Malcolm Lader

8 Sleep and its disorders

Robert G. Priest

9 Relevance of research in Parkinson's disease to psychiatry

Richard H. S. Mindham

10 Is the term 'psychosomatic' still of any value?

Desmond A. Pond

11 Prognosis in severe neurosis

Andrew C. P. Sims 
12 Hysteria Andrew Smith

13 Aspects of gender and its disorders J. P. Watson

14 Observations on psychiatric morbidity and premenstrual distress in women Anthony Clare

15 Aspects of the management of alcoholism

Terry A. Spratley

Section 3 General issues

16 Psychiatric morbidity in general practice: identification and treatment Anthony Clare

17 Psychological disturbances in adults with chronic physical illness

Pamela Taylor

18 Psychiatric diagnosis and classification John Copeland

19 Some aspects of the problem orientated medical record in general psychiatry

Anthony Fry

20 Multiple choice examinations in psychiatry

W. H. Trethowan

Section 4 Psychological treatments

21 The nature of psychological healing David Goldberg

22 Brief psychotherapy

Bernard K. Rosen

23 Marital therapies: an eclectic approach Sidney Crown

24 Behavioural approaches to marital and family problems

Michael J. Crowe

25 Treatment of sexual dysfunctions Patricia Gillan

26 Community management of patients with chronic schizophrenia by behavioural methods Jacqueline M. Atkinson 
Section 5 Physical treatments

27 A contemporary view of psychosurgery Paul K. Bridges

28 Drug treatment of depression

Thomas Barnes and Robin Braithwaite

29 Lithium in psychiatry

Brij M. Saran and Robin Jacoby

30 Benzodiazepines causing aggression

Raghu Gaind and Robin Jacoby 


\section{List of Contributors}

Atkinson, Jacqueline M., B.A.-Research Fellow, Department of Psychological Medicine, Guy's Hospital, London.

Barnes, Thomas, M.B., B.S.-Research Fellow, Department of Psychological Medicine, Guy's Hospital, London.

Braithwaite, Robin, Ph.D.,C.Chem., M.R.I.C.--Senior Clinical Biochemist, Poisons Unit, Guy's Hospital, London.

Bridges, P. K., M.D., Ph.D., M.R.C. Psych., D.P.M.-Consultant Psychiatrist, Geoffrey Knight Psychosurgical Unit, Brook General Hospital, London, and Senior Lecturer in Psychiatry, Guy's Hospital Medical School, London.

Clare, Anthony W., M.B., B.Ch., M.Phil (Lond), M.R.C.P.I., M.R.C. Psych.-Lecturer in Psychiatry, General Practice Research Unit, Institute of Psychiatry, and Honorary Senior Registrar, Bethlem Royal and Maudsley Hospitals, London.

Copeland, J. R. M., M.A., M.D., M.R.C.P., M.R.C. Psych., D.P.M.Professor of Psychiatry, University of Liverpool.

Crowe, M. J., M.A., D.M., M.Phil, M.R.C.P., M.R.C.Psych.-Senior Lecturer in Psychiatry, Institute of Psychiatry, and Honorary Consultant Psychiatrist, Bethlem Royal and Maudsley Hospitals, London.

Crown, Sidney, Ph.D., F.R.C.P., F.R.C.Psych.-Consultant Psychiatrist, The London Hospital, London.

Fleminger, J. J., M.A., M.D., F.R.C.P., F.R.C.Psych.-Physician in Psychological Medicine, Guy's Hospital, London.

FrY, Anthony, M.B., L.R.C.P., M.R.C.Psych., M.Phil., D.P.M.-Physician in Psychological Medicine, Guy's Hospital, London.

GaIND, Raghu, M. B., F.R.C.P., F.R.C.Psych., D.P.M. (Lond)-Physician in Psychological Medicine, Guy's Hospital, London

Gillan, Patricia, Ph.D.-Senior Psychologist, Rochford General Hospital, Honorary Psychologist, Maudsley Hospital, London.

Goldberg, David, D. M., F.R.C.P., F.R.C.Psych.-Professor of Psychiatry, University of Manchester.

GunN, John, M.D., M.R.C.Psych., D.P.M. (Lond)-Director of the Special Hospitals Research Unit, Institute of Psychiatry, London

HiRsch, Steven R., B.A., M.D., M.Phil., M.R.C.P., M.R.C.Psych.Professor of Psychiatry, Charing Cross Hospital Medical School, London.

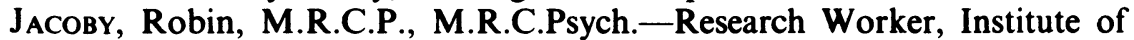
Psychiatry, and Honorary Senior Registrar, Maudsley Hospital, London.

LADER, Malcolm, D.Sc., Ph.D., M.D., F.R.C. Psych.-Reader in Clinical Psychopharmacology, Institute of Psychiatry, University of London.

Mindham, R. H. S., M.D., M.R.C.P., M.R.C.Psych.-Professor of Psychiatry, University of Leeds. 
Norton, Alan, D.M., F.R.C.Psych.-Honorary Consultant Psychiatrist, Bexley and Lewisham Hospitals, London.

Pond, D. A., M.D., F.R.C.P., F.R.C. Psych.-Professor of Psychiatry, The London Hospital Medical College, London.

Priest, Robert G., M.D., F.R.C.P. (Ed.), F.R.C. Psych., D.P.M.-Professor of Psychiatry, University of London, St Mary's Hospital Medical School, Harrow Road, London.

Rosen, Bernard, M.B., Ch.B., M.R.C.Psych., D.P.M.-Senior Lecturer in Psychiatry, Guy's Hospital, London

Saran, Brij M., M.B., B.S., Ph.D., F.R.C.P., M.R.C.Psych., D.P.M.Consultant Psychiatrist, Netherne Hospital, Surrey.

ScotT, P. D., C.B.E., M.D., F.R.C.P., F.R.C.Psych.—Late Consultant Psychiatrist, Maudsley and Bethlem Royal Hospitals, and to the Home Office.

Sims, Andrew C., M.A., M.B., B.Chir., M.R.C.S., L.R.C.P., M.R.C.Psych., D.Obst R.C.O.G., D.P.M.-Consultant Psychiatrist, All Saints' Hospital, Birmingham.

SmITH, Andrew, C., M.B., B.Chir., M.R.C.P. (Ed)., M.R.C.Psych., D.P.M.Consultant Psychiatrist, Bexley Hospital and Greenwich District Hospital, London.

SpRATLEY, Terence A., M.Phil., M.B., B.S., M.R.C.P., M.R.C.S., L.R.C.P.Consultant Psychiatrist, St Augustine's Hospital, Canterbury.

TAYLOR, Pamela, M.B., M.R.C.P., M.R.C.Psych.-Research Fellow, Department of Psychological Medicine, Guy's Hospital, London.

Trethowan, William H., M.B., B.Chir., F.R.A.C.P., F.R.C.P., M.R.C.S., L.R.C.P., F.R.C.Psych., D.P.M. (Lond).-Professor of Psychiatry and Dean of the Faculty of Medicine, University of Birmingham. 


\section{Preface}

This book is based on a selection from the lectures delivered at Bexley Hospital in September 1976 at the tenth of a bi-annual series of courses for Senior Psychiatrists. A comprehensive overview of current psychiatric knowledge is not intended, but we have tried to strike a reasonable balance in representing the diverse fields of recent enquiry and concern. We have chosen to focus on contemporary thinking, and research reviews, rather than on original research reports. We think that such a focus will meet a major need of the busy general psychiatrist: to keep abreast of developments on many fronts in a rapidly changing field. The book should also prove useful to psychiatrists preparing for higher examinations, and to colleagues in allied disciplines with a special interest in psychiatry.

The variety of contributions makes it hard to trace common themes, except in the most general terms. Perhaps the most striking is the multi-faceted approach to the understanding of psychological phenomena and the treatment of psychiatric disorder. Psychology, biology, physiology, pharmacology, all contribute, and eclecticism in treatment, with increasing concern for both effectiveness and economy, is the order of the day. Common to all the chapters is the attention given to clinical applications.

Our grouping of chapters into sections has, of necessity, been somewhat arbitrary with inevitable overlaps. However, we felt that these drawbacks were outweighed by the benefits of easier accessibility and lesser unwieldiness. We have tried to avoid repetition, but that too could not entirely be eliminated without doing injury to the arguments of separate contributors who happened to use similar reasoning or quote similar evidence in presenting their topic.

This volume is the first of a series. In future editions we will seek to compensate for the omissions that are unavoidable in a volume of this size and to update the content as new knowledge and thinking emerge.

Finally, we would like to thank those senior psychiatrists who attended the courses and gave us valuable feedback on the content and style of the lectures. Without their help we could not have been so confident in our task. We hope this book will stimulate as well as inform.

R.G.

B.L.H.

Keat's House, Guy's Hospital, London 


\section{Foreword}

Professor W. Linford Rees

Professor of Psychiatry, St Bartholomew's Hospital

and President of the Royal College of Psychiatrists

Psychiatry is a rapidly developing subject and for a number of years courses have been provided at Bexley Hospital, Kent, for senior psychiatrists. These courses fill a real need and have always been well attended. This book comprises a selection of the papers given during one of the courses, by established experts, relating to current themes and problems in psychiatry, and will be invaluable for the busy doctor who may have difficulty in keeping up with advances in psychiatry.

The topics covered are very interesting and of considerable diversity, ranging from highly topical matters, such as kidnapping and hostage-taking, discussed by a world authority on the subject, to psychopathy, aspects of schizophrenia and policy and mental health planning. There are also interesting contributions on the affective disorders, various aspects of the neuroses, dependency problems, psychosomatic and somatopsychic interactions, and problems of epidemiology and classification.

The final part of the book presents accounts of various forms of psychological treatment and various aspects of physical therapies in psychiatry.

This volume will be of great interest and benefit both to senior psychiatrists and to psychiatrists in training. It will also be of value to physicians and to others interested in the rapidly developing field of psychiatry. 


\section{Acknowledgements}

We would like to acknowledge the assistance of Mr Charles Fry, of The Macmillan Press Ltd, Miss Lilian Meekings, for secretarial assistance, and Merck, Sharp \& Dohme Ltd, for arranging support in the organisation of the conference held at Bexley Hospital in September 1976. We would like to thank all authors-especially those whose manuscripts arrived on time. 